\title{
Prospective single blinded randomised controlled trial of two orally administered activated charcoal preparations
}

\author{
Russell Boyd, Jacqueline Hanson
}

\begin{abstract}
Objectives-To compare two activated charcoal preparations (Carbomix and Actidose-Aqua) in terms of amount ingested and incidence of vomiting after ingestion.

Methods-Single blinded prospective randomised controlled trial.

Results-The mean amount of charcoal ingested was Carbomix 26.5 g, ActidoseAqua $19.5 \mathrm{~g}$. The mean difference was $7 \mathrm{~g}$ (95\% confidence interval (CI) 1.5 to 12.4 g). The incidence of vomiting was for the Carbomix 6\% and the Actidose-Aqua 8\%. The mean difference in vomiting was $2 \%$ (95\% CI -0.8 to 4.8 )

Conclusions-Carbomix administration results in an increased amount of activated charcoal ingested after oral administration. Rates of vomiting after activated charcoal administration were low when compared with previously reported rates. ( $F$ Accid Emerg Med 1999;16:24-25)
\end{abstract}

Keywords: charcoal; decontamination; oral administration; poisoning

The administration of activated charcoal products in acute poisoning has now become firmly established as standard policy in most emergency departments. Its efficacy has been established for both single and multiple dose regimens. ${ }^{1-3}$ Various differing forms of "activated" charcoal (activated in the sense that their surface area is artificially enhanced) are now commercially available. ${ }^{4}$ They offer similar properties in terms of surface areas (approximately $1000 \mathrm{~m}^{2} / \mathrm{g}$ ) and absorption (approximately $750 \mathrm{mg} / \mathrm{g}$ in vitro). The original preparations available in the UK were presented as anhydrous powders, reconstituted with tap water, to form a "slurry" necessitating relatively large administration volumes. The current brand leader in the UK in terms of licenced preparation of such type is ActidoseAqua (Cambridge Laboratories).

No randomised controlled trials have been conducted in Europe comparing the delivery mechanisms and work from North America principally concerns the effect of preparation type on patient tolerance rather than compliance. $^{3}$ This lack of evidence based medicine is unusual as it is perceived as a major problem in emergency departments in that various delivery mechanisms for such an unpalatable product, with known efficacy, have not been validated yet. The aim of this single blinded prospective randomised controlled study was to compare the older "slurry" type preparation of Carbomix with the newer suspension style product of Actidose-Aqua to determine actual amounts of charcoal ingested after oral administration and to ascertain the rates of vomiting after administration of the two preparations.

\section{Methods}

This study was designed as a single blinded randomised controlled trial to determine the efficacy of ingestion of the two delivery mechanisms for activated charcoal. Approval from the Royal Preston Hospital medical ethics committee was obtained before initiation of the study. Ninety seven sequential patients seen and assessed in the accident and emergency department of the Royal Preston Hospital were prescribed oral administered activated charcoal (50 g of activated charcoal in each preparation) by the assessing medical staff in accordance with advice from the National Poisons Bureau on treatment of the presenting intoxication. Each patient was given a verbal explanation of the study and verbal consent was obtained before admission into the study. The patients were then assigned by means of computer generated random numbers in sealed envelopes to receive one of two of the orally administered activated charcoal preparations, either Carbomix or Actidose-Aqua.

The Carbomix was prepared to a slurry with $400 \mathrm{ml}$ tap water as recommended by the manufacturers with the Actidose-Aqua being ready prepared $(240 \mathrm{ml}$ of preformed suspension). Each preparation was administered in an opaque covered plastic drinks container with the contents agitated every five minutes to prevent settling over an observed 30 minute time period. Each patient was asked to drink as much of the product as was possible irrespective of the product type. Each container was weighed using an electronic weighing set (all \begin{abstract}
"slurry" preparations is Carbomix (Penn). In the last 18 months newer preparations have been introduced to the UK whose physical characteristics, for example taste and consistency, lend themselves specifically to oral administration. ${ }^{5}$ This has occurred alongside greater interest in the oral administration of charcoal as recent trends in toxicological practice moves away from orogastric lavage. ${ }^{6}$ These preparations contain sweeteners and come in a suspension form requiring reduced "carrier" volumes for administration. The most recently

Accident and
Emergency

Preston Hospital

R Boyd

Correspondence to:

Dr R Boyd, Department Emergency Medicine, Hope

Accepted 7 August 1998
\end{abstract}

\footnotetext{
(1)
} 
measurements in grams) at time of administration and 30 minutes after administration. The relative densities of actual grams of charcoal/ gram of product were calculated from the supplied product information sheets. A written log of vomiting was kept to ascertain the rates of vomiting in the 30 minutes immediately after administration of each product. Observation for 30 minutes was the maximum time period feasible in terms of nursing staff availability.

\section{STATISTICAL ANALYSIS}

All data was analysed on a "Mini-tab" statistical package using a two tailed $t$ test to ascertain the presence of a significant difference between the treatment groups.

\section{Results}

Ninety seven patients were randomised and data were completed for all patients. There were 47 administrations of the Carbomix preparation with 50 of the Actidose-Aqua preparation. The mean (SD) amount of charcoal drunk via the two routes was Carbomix 26.5 (13.3) $\mathrm{g}$ and Actidose-Aqua 19.5 (13.7) g. The mean difference in amount of charcoal delivered was $7 \mathrm{~g}$ with $95 \%$ confidence interval (CI) 1.5 to $12.4 \mathrm{~g}$. Two tailed $t$ test showed a statistically significant difference between the two routes $(p=0.013)$.

Vomiting after ingestion occurred in a mean of $7 \%$ of all patients. The individual rates of vomiting for each product were Carbomix $6 \%$ and Actidose-Aqua $8 \%$. The mean difference was $2 \%(95 \% \mathrm{CI}-0.8$ to 4.8$)$. There was no statistical difference in rates of vomiting between the groups.

\section{Discussion}

The use of activated charcoal is now recommended as a key method for gastric decontamination. ${ }^{7}$ No evidence based research exists to compare the various preparations in terms of the efficacy of their delivery mechanisms. Our study has been designed to compare two differing delivery mechanisms for orally administered charcoal. This study has shown that there is a significant difference between the administration systems in terms of the actual amount of charcoal ingested. It also suggests that even for the best preparation of oral activated charcoal there is considerable shortfall between the dose prescribed and that drunk. This study was not designed to demonstrate any difference between the two preparations in terms of reducing symptoms or complications from the actual poisoning. This trial does not have the necessary power to show clinical differences in effectiveness and to date no randomised controlled trials have been conducted to show the clinical effectiveness of oral activated charcoal. However, as has been previously shown, a ratio of $10 \mathrm{~g}$ charcoal/ $1 \mathrm{~g}$ toxin $^{8}$ is required to absorb products in vivo. It would seem significant, in terms of comparing preparation types, that there is a mean difference in potential absorptive capacity of $0.7 \mathrm{~g}$ toxin, based on a mean difference of $7 \mathrm{~g}$ activated charcoal ingested, between the preparations after administration.

The incidence of vomiting is reported overall as $7 \%$ with the rates for Carbomix $6 \%$ and for Actidose-Aqua 8\%. These represent rates lower than the $12.5 \%$, which are the only rates that have previously been described. ${ }^{9}$ It is difficult to know whether to ascribe the vomiting in poisoned patients to the toxin itself or the administered charcoal preparation as no evidence based work has been performed to answer this question. However, in our study, the patients were blinded as to the actual colour and viscosity of this potentially unpalatable preparation and it is noteworthy that our rates of vomiting are indeed lower than in the previous study where no blinding was reported. ${ }^{6}$ This could suggest that rates of vomiting may in fact be influenced by the odour and appearance of the charcoal products themselves.

\section{Conclusion}

Actidose-Aqua, which is one of the newer preparations of activated charcoal, is thought to have better palatability characteristics. ${ }^{5}$ However this study produces strong evidence to suggest that slurry preparations such as Carbomix result in an increased amount of activated charcoal ingested than ActidoseAqua (a suspension product).

We would like to thank Dr Chris Sutton for his invaluable statistical advice and most importantly the nursing staff at the Royal Preston Hospital Accident and Emergency Department.

1 Neuvonen PJ, Vartianen M, Tokalo O. Comparison of activated charcoal and ipecac syrup in prevention of drug vated charcoal and ipecac syrup in prevention

2 Anonymous. Repeated oral activated charcoal in acute poisoning [editorial]. Lancet 1987;i:1013-5.

soning [editorial]. Lancet 1987;i:1013-5.
McFarland AK, Chyka PA. Selection of activated charcoal products for the treatment of poisonings. Ann Pharmacother 1993;27:358-61.

4 British Medical Association/Royal Pharmaceutical Society of Great Britain. British national formulary. London: Pharmaceutical Press, 1997

5 Cambridge Laboratories. Actidose-Aqua product information. Richmond House, Newcastle-upon-Tyne: Cambridge Laboratories, 1996.

6 Henry JA, Hoffman JR. Continuing controversy on gut decontamination. Lancet 1998;352:420-1.

7 Donovan JW. Activated charcoal in management of poisoning. Postgrad Med 1987;82:52-8.

$8 \mathrm{Chin} \mathrm{L,} \mathrm{Pichioni} \mathrm{AL,} \mathrm{Bourn} \mathrm{WM.} \mathrm{Optimal} \mathrm{antidotal} \mathrm{dose} \mathrm{of}$ activated charcoal. Toxicol Appl Pharmacol 1973;26:103-8.

activated charcoal. Toxicol Appl Pharmacol 1973;26:103-8. Minocha A, Wiley SH, Chabbra DR, et al. Superior efficacy
of sorbitol cathartics in poisoned patients. Vet Hum Toxicol 